\title{
A Amazônia no Pós-guerra E a CONSTRUÇÃo da Rodovia BELÉM-Brasília ${ }^{1}$
}

Rômulo de Paula Andrade ${ }^{2}$

RESUMO: O objetivo do presente artigo é apontar um breve panorama das políticas estatais para a região amazônica após a Segunda Guerra Mundial, tendo como culminância a construção da Rodovia Belém-Brasília, uma das maiores intervenções estatais na região. A intenção é problematizar o percurso histórico da região, entrecruzando-o com os contextos nacionais e internacionais, frente à emergência do desenvolvimento como uma bandeira das nações industrializadas. Sob a égide do desenvolvimento, políticas públicas foram formuladas com diferentes preocupações, como a criação de estradas para acabar com o "isolamento histórico". Tal ideia reafirmou uma concepção recorrente sobre a Amazônia: uma região despovoada, insalubre, dona de uma natureza selvagem e, principalmente, inimiga do progresso. Este enquadramento da região Amazônica não representava uma novidade, mas tratava-se da adaptação de mitos e construções anteriores a esse novo período do desenvolvimento. Inicialmente, vamos traçar um panorama das intervenções estatais e dos debates políticos envolvendo a região amazônica no período democrático (1946-1964).

PALAVRAS-CHAVE: Amazônia. Belém-Brasília. Desenvolvimento. Poder. Intervenção estatal.

O cenário mundial pós-guerra e a reconstrução da Europa pautada pelo Plano Marshall contribuíram para que houvesse alteração nas reformulações teóricas acerca do papel dos Estados nacionais nos processos de desenvolvimento dos países latino-americanos. Passou a ser predominante a idéia de que a intervenção do Estado na economia não era somente benéfica, mas necessária para o desenvolvimento econômico. Afirmou-se uma visão sobre o papel do Estado nos processos de desenvolvimento que se contrapunha a um conjunto de idéias que defendiam o mercado como o melhor instrumento para

\footnotetext{
Artigo produzido a partir das reflexões oriundas do quinto capítulo da tese de doutorado, "A Amazônia na era do desenvolvimento: saúde, alimentação e meio ambiente (1946-1966)", defendida no ano de 2012, junto ao Programa de História das Ciências e da Saúde, da Casa de Oswaldo Cruz/ Fiocruz, Rio de Janeiro.

2 Doutor em História das Ciências, Professor da Secretaria Estadual de Educação do Rio de Janeiro.
} 
dirigir a alocação dos recursos com vistas à promoção do desenvolvimento de diferentes regiões e nações. Dessa forma, as décadas que sucederam a Segunda Guerra Mundial foram marcadas, em termos gerais, pelo relativo otimismo em relação às possibilidades de generalização do desenvolvimento e à necessidade da participação do Estado nacional nestes processos. Ganhou também impulso o pressuposto da eficácia do planejamento do desenvolvimento, que poderia ser alcançado por meio de uma racionalização da aplicação de capitais, sob a coordenação estatal (ABREU E NUNES, 2004).

Este contexto relaciona-se diretamente com os planos e políticas para a Amazônia no pós-guerra. Com o fim da ditadura de Getúlio Vargas, o país passou por um período democrático, tendo como ponto de partida o governo de Eurico Gaspar Dutra (1946-1951). Após as eleições de 2 de dezembro de 1945, os eleitores escolheram os deputados que fariam a quarta Constituição do Brasil desde 1889. A República que se abre com o fim da ditadura do Estado Novo e com a promulgação da Constituição de 1946 representa o período da experiência liberal-democrática, caracterizada pela dominância de três grandes partidos na cena da política nacional: PSD, PTB e UDN. Estas agremiações políticas conviveram através de acordos com outros partidos de menor porte e de importância eleitoral mais regionalizada e colaboraram para a construção de um período democrático.

A Constituição de 1946 ratificava a importância que a região tinha adquirido no plano federal, ao apontar, em seu artigo 199, para a "valorização econômica da Amazônia".

Art 199 - Na execução do plano de valorização econômica da Amazônia, a União aplicará, durante, pelo menos, vinte anos consecutivos, quantia não inferior a três por cento da sua renda tributária. Parágrafo único - Os Estados e os Territórios daquela região, bem como os respectivos Municípios, reservarão para o mesmo fim, anualmente, três por cento das suas rendas tributárias. Os recursos de que trata este parágrafo serão aplicados por intermédio do Governo federal (BRASIL, 1946).

Ampliando o recorte temporal, este dispositivo constitucional está relacionado diretamente ao novo lugar da Amazônia no rol das preocu- 
pações federais desde os anos de 1940, com projetos políticos como a Marcha Para o Oeste, que previa a ocupação da região por elementos locais; o Plano de Saneamento da Amazônia, gestado por quadros destacados da área de saúde pública da época; e a Batalha da Borracha, que previa um reaquecimento da produção gomífera amazônida com vistas ao abastecimento das forças aliadas. O drama humano causado pela fracassado boom artificial da borracha, com o desaparecimento e morte de milhares de nordestinos (chamados pela propaganda oficial da época de Soldados da Borracha) que foram à região, estava na agenda de discussões da constituinte, contando com uma Comissão Parlamentar de Inquérito. Mesmo não obtendo grandes resultados práticos esses eventos servem como base para localizar a região nos discursos governamentais da época (CAMPOS, 2006; SECRETO, 2007).

Além do contexto nacional, é necessário relembrar o panorama mundial dos anos 1930, quando a idéia de desenvolvimento planejado passou a integrar os projetos governamentais, ganhando fôlego após a Segunda Guerra Mundial. Nesse contexto, a Amazônia passou a ser tratada à luz das modernas técnicas de planejamento. $\mathrm{O}$ dispositivo constitucional sobre a valorização econômica da Amazônia ocorreu devido à necessidade de serem geradas outras alternativas econômicas e sociais para a localidade, pois com o fim da Segunda Guerra Mundial, tinha acabado a motivação original para o aumento de produção da borracha (D’ARAÚJO, 1985).

No ano de 1947, diante da crise que se instalara no setor, criou-se a Comissão de Defesa da Borracha, pelo decreto 23.990, de 31 de outubro do mesmo ano, que mantinha por um período de três anos os preços mínimos para o produtor e protegia os industriais da borracha no mercado interno. O governo monopolizou a compra e estocou quantidades do produto que excedessem as necessidades do mercado nacional (idem). Em decorrência do dispositivo constitucional de 1946, foi instituída, na Câmara dos Deputados, a Comissão Especial do Plano de Valorização Econômica da Amazônia, presidida pelo deputado Leopoldo Peres (PSD/AM), autor da proposta presente no artigo 199. Vários projetos foram então apresentados, resultando, em 1951, na execução do Plano de Valorização Econômica da Amazônia.

A região também foi inserida no Plano SALTE (sigla que sig- 
nificava Saúde, Alimentação, Transporte e Energia) do presidente Eurico Gaspar Dutra, anunciado em 1948 e promulgado em 18 de maio de 1950, através da lei n. 1.102. Em campanha eleitoral, Getúlio Vargas retornou à Amazônia em 1950 e prometeu continuar o trabalho que fora interrompido pela situação de guerra. No discurso, Vargas culpou o "vazio demográfico" pelo atraso da região:

Vim, amigos da Amazônia, para dizer-vos que, se eleito (...) hei de promover medidas adequadas ao reforçamento das vossas energias, pondo em execução o vasto programa que a guerra interrompeu. Nas outras questões que dizem respeito, administrativamente, ao vosso Estado, quero reafirmar-vos que persisto nos planos antigos. O grande inimigo da vossa prosperidade é, sem dúvida, o deserto, é a fraqueza dos índices demográficos. (...) O homem só, isolado, como Robinson Crusoé - é homem perdido. Vivemos socialmente, progredimos em sociedade. Assim, o que necessitamos é evitar a dispersão e promover o aglutinamento das populações (VARGAS, 1950).

A razão histórica apontada pelos governantes como a responsável pelo atraso da Amazônia, a dispersão demográfica, é presença constante nos discursos presidenciais desde o início da República. Segundo Pádua, a situação de abandono das fronteiras geográficas do Centro-Oeste e da Amazônia transformou-se em um "espectro geopolítico" que rondou o Estado brasileiro ao longo do século XX, especialmente após a Revolução de 30 (Pádua, 2000). A discussão se repetiu nos anos 1950 sob um novo contexto, quando os discursos se multiplicaram e os debates tornaram-se mais complexos devido à maior participação política no regime democrático e à conseqüente ampliação do espaço adquirido para a discussão pública.

A discussão política sobre a região amazônica é um exemplo disso. No período histórico privilegiado neste trabalho, a multiplicação das vozes antes silenciadas pela ditadura de Getúlio Vargas renovou as discussões acerca dos rumos do país e, no que tange ao nosso trabalho, da região amazônica. Querelas envolvendo diferenças regionais

e partidárias permearam os debates iniciais sobre a prometida recuperação da região, cristalizada no dispositivo constitucional da Carta Magna de 1946. O desaparecimento dos Soldados da Borracha foi o primeiro episódio 
envolvendo a Amazônia no plenário do Congresso Nacional, então ocupado com a feitura de uma nova Constituição.

Antigos opositores do Estado Novo se aproveitavam da nova correlação de forças para realizar uma Comissão Parlamentar de Inquérito (CPI) a fim de investigar o drama dos trabalhadores enviados à Amazônia para um esforço de guerra, questão que povoava os noticiários da época. Números extraoficiais davam conta do desaparecimento de 30.000 trabalhadores e invadiam o noticiário cotidiano, livres da censura do Departamento de Imprensa e Propaganda (DIP) do governo Vargas. Este fato relaciona-se diretamente com o lugar que a Amazônia passou a ocupar nos projetos do novo contexto que então surgia: a constituição brasileira de 1946 dedicou 3\% do orçamento total do governo federal para um programa de Valorização Econômica da Amaz̧ônia, visando o soerguimento e recuperação da região.

No Governo Dutra (1946-1950), foram lançadas as pedras fundamentais dos planos de recuperação econômica para a região amazônica, através do dispositivo constitucional e da discussão sobre a criação de um instituto internacional de pesquisas, a Hileia Amazônica. Este debate trouxe à tona os "fantasmas" de internacionalização da Amazônia, presentes também em períodos posteriores da história republicana brasileira. Tais acontecimentos conferiram contornos nacionalistas aos rumos das querelas sobre os projetos para a região. Além disso, 1946 foi o ano em que se formou a Comissão para a Valorização Econômica da Amazônia (CPVEA) para fiscalizar a região e propor ações. Durante o segundo Governo Vargas (1951-1954), foi criada oficialmente a Superintendência de Valorização Econômica da Região Amazônica (SPVEA), órgão responsável pela coordenação dos recursos destinados pela Constituição brasileira. Através da criação da primeira experiência regional de planejamento do país, outras ações foram planejadas, como o Programa de Emergência, documento redigido em 1952 a partir da reunião de grupos de discussão sobre as áreas consideradas essenciais para a recuperação.

Uma importante ruptura deste processo foi o suicídio de Getúlio Vargas, em agosto de 1954. A presidência, durante esse período, foi ocupada por Café Filho. No ano de 1955, foi publicado o Primeiro Plano Quinquenal, 
principal documento de planejamento para o trabalho na região, o qual que previa metas que seriam avaliadas em 1960. Foi durante o governo Juscelino Kubitschek (1956-1961) que a questão do desenvolvimento se tornou mais explícita, com a Amazônia enquadrada neste contexto. O diagnóstico para o isolamento da região passava por programas de cooperação entre agências nacionais e internacionais, além da construção de estradas de rodagens. Foi nessa época que a principal obra por parte da SPVEA foi construída: a rodovia Belém-Brasília. Trabalhos na área de saúde também mereceram destaque nesta época, como a experiência de cloroquinização do sal de cozinha para a erradicação de malária na região. ${ }^{3}$ Agências internacionais, como a Food and Agriculture Organization of the United Nations (FAO), trabalharam ativamente na região, realizando pesquisas sobre a alimentação dos homens da Amazônia e investigando as possibilidades de criar uma indústria madeireira. Organizações nacionais, como a Comissão Nacional de Alimentação (CNA) também buscaram mapear, ainda que de forma precária, os hábitos alimentares dos nativos.

O Plano de Valorização Econômica da Amazônia não ficaria incólume ao conturbado contexto dos anos de Jânio Quadros (1961) e João Goulart (1962-1964). Nesse período, aumentaram as críticas à agência regional, taxada pelos opositores como um meio para corrupção e loteamento de cargos. O curto período da SPVEA no período ditatorial (1964-1966), então sob o comando de uma interventoria militar, serviu para a elaboração de relatórios que visavam a apontar os erros do passado para não repeti-los no futuro. Em 1966, a agência foi desfeita e refundada, passando a se chamar Superintendência do Desenvolvimento da Amazônia (SUDAM). Na concepção do governo militar, representaria a nova tentativa de incorporação da região amazônica ao restante do país. A recém-criada agência teria sua relevância divulgada a partir de uma contraposição ao governo anterior, considerado pelos militares como corrupto e à mercê das articulações das facções políticas.

Longe de representar um período linear, o percurso histó-

3 O Método Pinotti consistia em adicionar a cloroquina, um medicamento contra a malária, ao sal de cozinha. O sucesso do chamado "sal Pinotti" ocorreu em grande escala devido à possibilidade do sal conseguir atingir regiões que a borrifação do DDT não alcançava, além de ser mais barato. Ver: SILVA \& HOCHMAN, 2011. 
rico (1946-1964) aqui analisado apresentou rupturas, permanências e intensos debates sobre os rumos da SPVEA e do país. No âmbito internacional, esse período foi intitulado por um grupo de pesquisadores como a Era do Desenvolvimento, quando a crença sobre o avanço tecnológico das instituições científicas deu origem a um discurso que se pretendia hegemônico e que criava parâmetros de 'desenvolvimento' e ‘subdesenvolvimento' a partir dos padrões estabelecidos pelos países ricos. Conceito pertinente aos interesses das disputas geopolíticas resultantes da Guerra Fria, a criação dos 'subdesenvolvidos' seria uma forma de afastar esses países da influência soviética. Além do discurso, o desenvolvimento resultou em ações que buscavam atender a uma demanda histórica para as regiões consideradas periféricas. O conceito de desenvolvimento e sua contraparte, o subdesenvolvimento, longe de serem ideias fechadas, estiveram em constante discussão no curso dos anos. Existiu certo desafio lançado pelas potências ocidentais sobre o desenvolvimento de regiões pobres; estas, por sua vez, reconfiguraram o conceito e o apropriaram às suas necessidades. ${ }^{4}$

Uma perspectiva que perpassa as ações do Estado brasileiro na década de 1950 era a de integração nacional. Ideia esta executada principalmente durante o governo de Juscelino Kubitschek através de uma melhora da infraestrutura e de obras de engenharia de transporte, que apresentaram certa eficácia no avanço da fronteira agrícola e econômica. Foi o caso da rodovia Belém -Brasília, que atravessou - e atravessa até os dias atuais - territórios dos estados do Pará, Maranhão e Goiás. Colonização, estradas e grandes projetos constituíram assim, elementos do pilar da política de integração nacional de Juscelino Kubitschek. Para realizar este tento, foram mobilizadas pelos atores daquele período concepções acerca da formação histórica, civilização, saúde e natureza da Amazônia.

A ideia de que a natureza submetia o homem a um regime de carestia permanecia, mas, graças às ferramentas disponíveis pelos homens daquele período, isso não seria mais um problema. Constituída como um entrave para o progresso, a natureza poderia ser vencida com os tratores e máquinas que o

\footnotetext{
F Esta concepção está presente no grupo de estudos intitulado Post-development studies. Esta definição encontra-se em Sachs (1999).
} 
governo possuía àquele momento. A vitória do homem sobre a terra se transformou, no período de construção da rodovia, em uma epopeia que representaria a vitória do novo bandeirantismo, presente no governo de Juscelino Kubitschek. O homem, considerado um elemento estranho àquele lugar, e sua saúde, despertaram preocupações dos homens de ciência daquele período. A Amazônia era vista como um lugar em que malária encontrara um lar, e de lá nunca sairia. Com a ascensão da ciência da nutrição brasileira, essa doença e muitas outras seriam fruto do péssimo regime alimentar daqueles homens.

\section{A Belém-Brasília e o governo Juscelino Kubitschek}

Em 1958, o Congresso Nacional autorizou o início da construção da rodovia Belém-Brasília. Longe de significar uma mera efeméride, a construção da BR-14, também chamada de Transbrasiliana, mobilizou um poderoso arsenal de propaganda política, envolvendo reportagens, livros e documentários, com o objetivo de defender o projeto, alvo de críticas da oposição da época. A análise das fontes históricas produzidas no período dá luz ao pensamento social brasileiro sobre a integração nacional, e a um pensamento (anti)ambiental presente nos discursos oficiais. Desta forma, apontaremos as visões de natureza que emergem durante construção da rodovia, bem como o lugar do "interior" no projeto nacional desenvolvimentista capitaneado por Juscelino Kubitschek.

De acordo com Moreira, o governo JK foi, de longe, o mais bem-sucedido da experiência democrática (1946-1964), pois a partir de um quadro social e político tenso, junto a interesses divergentes, conciliou o processo democrático e a intensificação do desenvolvimento do tipo capitalista (MOREIRA, 2003). Durante sua administração, o desenvolvimentismo, ou o nacional-desenvolvimentismo, consolidou-se como um estilo de governo e como um projeto social e político. A "linguagem do desenvolvimento", balizada por números e estatísticas, não fazia parte do estilo político da época. Desta forma, contanto com grande apoio da população, o presidente pôde realizar o Plano de Metas, um documento essencialmente econômico, dividido em trinta objetivos.

A Belém Brasília está localizada como um apêndice da "meta-síntese", a construção de Brasília. A nova capital, em conjunto com o "cruzeiro rodoviário" composto pelas rodovias Belém-Brasília, Acre/Brasília, Forta- 
leza/Brasília, Belo Horizonte/Brasília e Goiânia/Brasília. A análise econômica da equipe de $\mathrm{JK}$ apontava que um dos principais pontos de estrangulamento do desenvolvimento industrial era a falta de comunicação entre as regiões industriais do sudeste e as zonas agroprodutoras do interior (MOREIRA, 2003). O interior, por sua vez, possuía um mercado consumidor em potencial de produtos industrializados, subaproveitado por falta de meios e vias de comunicação. Desta forma, dificilmente, o salto industrial do nacional-desenvolvimentismo alcançaria sucesso. Conforme aponta Moreira, a "integração nacional" composta pelo cruzeiro rodoviário e por Brasília realmente funcionou como um passo contundente no processo de integração territorial e do sistema produtivo nacional, representado pela carência de vias de comunicação que sufocava o crescimento global do país (MOREIRA, 2003).

Os representantes das regiões que seriam agraciadas pelas construções das estradas e de Brasília logo perceberam as novas possibilidades que estes projetos trariam. As obras passaram a ser definidas como o retorno definitivo da "Marcha para o Oeste", programa de governo executado durante o Primeiro Governo Vargas, cujos objetivos eram a ocupação e o saneamento dos rincões do Brasil. Os ares de "modernidade" e "desbravamento" foram criticados por Otávio Velho. Para o autor, há uma tendência em identificar o início do soerguimento econômico da Amazônia com a construção da Belém-Brasília e a criação de agências de desenvolvimento, o que seria uma meia-verdade, pois nenhuma dessas medidas, por si, teria efeito considerável, não fosse a existência de certas precondições que vinham lentamente amadurecendo (VELHO, 2009). De acordo com Velho, apesar do peso crescente das iniciativas do Estado no processo de desenvolvimentos, o fato é que elas só se tornam em geral viáveis quando carregadas do senso de aproveitamento de determinados movimentos sociais, como foi o caso da rodovia Belém-Brasília. Segundo Velho, por desinformação, esta obra continua a ser identificada erroneamente como um esforço absolutamente heróico de ação sobre um deserto; fato contestado por outro apontamento: o incremento demográfico regional experimentado pela região nos anos de 1950 (VELHO, 2009). Dessa forma, tais obras vieram ao encontro de um processo anterior que já estava em curso.

A "redescoberta da Amazônia" é algo constante nos regi- 
mes republicanos do século XX. Ocorreu, de certa forma, a ressignificação no curso deste período de imagens e representações sobre a Amazônia, vista constantemente como um "vazio" demográfico, cuja natureza fazia do homem um "estrangeiro em sua própria terra", parafraseando um autor sempre citado pelos governantes: Euclides da Cunha. Se nos anos Vargas, o "Inferno Verde” (alcunha criada pelo romancista Alfredo Rangel e também constantemente utilizada) seria domada pelo homem, a integração capitaneada por Juscelino Kubitschek estava inserido num processo que tem origem na Carta Magna de 1946, que previa o repasse de 3\% do orçamento nacional para a região amazônica, em prol de uma valorização econômica, em conjunto com a ação da então contestada agência regional Superintendência de Valorização Econômica da Amazônia (SPVEA), que, até aquele momento, apresentava resultados pouco relevantes, além de sofrer constantes denúncias dos parlamentares oposicionistas.

\section{Enguiçou, morreu: loas e críticas à Belém-Brasília}

Como apontamos, para Velho, a "descoberta da Amazônia" seria fruto de uma desinformação. Porém, é importante ressaltar que tal "desinformação" foi articulada a partir de um grande aparato de propaganda política envolvendo reportagens favoráveis, filmes, fotos e discursos presidenciais, que intentaram levar ao público a construção da rodovia como uma vitória inegável do homem sobre a natureza. Este aspecto revela aos olhares contemporâneos a relação existente entre o projeto nacional-desenvolvimentista e a natureza daquele período. Uma amostra do esforço em colocar a Belém-Brasilia como um exemplo de integração da Amazônia ao restante do país encontra-se nas próprias memórias escritas por Juscelino Kubitschek, em Por que construí Brasilia. De acordo com o então presidente, a rodovia estava integrada a um processo histórico anterior, formando assim, a concretização de um sonho de vários brasileiros de gerações anteriores. O primeiro "desafio à floresta" seria o do tenente Pedro Teixeira que conduzira o capitão-mor Jerônimo de Albuquerque pela floresta até São Luís do Maranhão (KUBITSCHEK, 2000). Paulo de Frontin, devido ao plano de ligar Pirapora (MG) a Belém, também estava inserido neste referencial histórico, bem como Getúlio Vargas, por ocasião do Plano Geral de Viação Nacional em 1934 (KUBITSCHEK, 2000). Dessa forma, JK seria o responsável por cumprir 
esta missão histórica. Porém, o grandioso projeto do governo Kubitschek não passaria sem críticas da imprensa e políticos. Roberto Menna Barreto, entusiasta da rodovia, publicou suas impressões de viagem no livro Aventura Através do Progresso, no qual apontou as críticas direcionadas à rodovia:

Pouco sabe o Brasil sobre a BR-14. Desse pouco, boa parte constitui impressão sem qualquer fundamento, temores fantásticos. É como se o país acreditasse em um novo Mar Tenebroso, no meio do seu próprio território. Como explicar tais receios e despropósitos? Consultamos as reportagens publicadas em duas revistas. Uma delas clama no título: "Três mulheres vencem a estrada condenada à morte!" E legendas: A cada passo, no leito da estrada, reduzido a um caminho de índios (ou de onças) os caminhões atolam... (BARRETO, 1965:08).

À época da construção, entre 1958 e 1960, outras críticas foram dirigidas à Belém-Brasília. Plínio Coelho, então governador do Amazonas, teria classificado a obra de "Sonhovia" (VAITSMAN, 1958). Mauro Borges, senador pelo Partido Social Democrata (PSD) afirmou em plenária que "Fala-se até mesmo que será caminho somente das onças, e adverte-se, por alguns jornais, aos motoristas que lá trafegam, com o sinistro aviso 'enguiçou, morreu" (BRASIL, 1959, p. 620). Segundo Borges, a estrada nada mais era que um grande trecho da Anápolis-Belém, que já estava em construção desde a década anterior. A única novidade seria o fato de governo enfim, conceder à rodovia alta prioridade (BRASIL, 1959, p. 620). Ferro Costa, deputado pela UDN, lançou suspeitas sobre irregularidades na construção da Belém-Brasília, tendo como resposta uma nota oficial do superintendente da SPVEA, Waldir Bouhid (PINTO, 2009).

Talvez o mais conhecido comentário seja o de Jânio Quadros, quando, em 1959, teria afirmado que a "A Belém-Brasília é a estrada das onças. Liga o nada a lugar nenhum". ${ }^{5}$ O então governador de São Paulo enviou carta para o jornal responsável pela vinculação desta frase exigindo retratação: "Como poderia, em sã consciência, como filho de Mato Grosso, ser contrário aos empreendimentos públicos que venham enriquecer a sua região natal? Há tempo me foi dado opinar em Goiás que o 'Brasil precisa de ser governado de costas para o mar” (BRASIL, 1959, p. 622). De acordo com Lúcio Flávio Pinto,

Esta frase e a autoria a Jânio Quadros foi publicada recentemente na revista Veja especial Brasília 50 anos. 
o verdadeiro autor da frase fora o presidente da Associação Comercial do Rio de Janeiro, Rui Gomes de Almeida (PINTO, 2009).

Gabriel Hermes, deputado federal pela União Democrática Nacional (UDN/PA) traz outro tom em suas críticas, feitas em 1958. Inicialmente, Hermes citou o estudo de David Azambuja, que afirmara que a destruição das reservas florestais do Brasil avançava em uma proporção de 30 quilômetros quadrados anualmente e que, em 25 anos, o país não teria mais florestas (BRASIL, 1959, p. 505). Como exemplo, o deputado cita a Estrada de Ferro de Bragança, cujos 200 quilômetros de mata teriam sido devastados pelos nordestinos que ali se instalaram, sem nenhuma orientação ou colaboração do Governo Federal (BRASIL, 1959, p. 505). O Udenista cita também uma matéria do periódico Correio da Manhã, onde é apontado que grandes incêndios estavam calcinando as florestas ao longo da Belém-Brasília em conjunto com a imigração espontânea de nordestinos, que por sua vez derrubavam árvores e lançavam fogo nas matas, resultando num "desperdício imenso da riqueza florestal e num prejuízo tremendo para o futuro" (BRASIL, 1959, p. 506). Por fim, o deputado aponta que:

O grande mal que se faz não será recuperado com facilidade, porque uma floresta secular não se recompõe nem se replanta em dez nem vinte anos (...) agora se fala com tanto entusiasmo numa estrada que vai ser útil não sei daqui a quantos anos, que é a Belém-Brasília. Que não se faça desde já, agora, nesse caminho de dois mil quilômetros, a desastrada derrubada que já se processou naqueles caminhos longos de Belém a Bragança (...) Aqui fica uma (...) advertência para que pensem no mal que representa este caminhar, este derrubar de árvores, esta marcha sem nenhuma planificação como a que está sendo feita ou que se vai fazer ligando Belém a Brasília (BRASIL, 1959, p. 506).

Gabriel Hermes fez, ao longo de sua trajetória política, diversos pronunciamentos críticos em relação à SPVEA e aos projetos do governo para a Amazônia. Sendo do grupo de oposição ao superintendente Waldir Bouhid (PSD), o deputado sempre teve um posicionamento contrário aos projetos do governo para a região. Importante ressaltar discursos dissonantes sobre a rodovia, porém a propaganda oficial se impôs sobre estas falas, tendo em vista a pluralidade de mídias utilizadas pelo governo Kubitschek para divulgar a "nova" descoberta da Amazônia. 


\section{A conquista da selva: uma aventura ciclópica}

Por mais que o governo JK não tivesse um aparato de propaganda estatal institucionalizado, como no Estado Novo de Getúlio Vargas, é possível identificar um núcleo de elaboração, sistematização e divulgação, localizada no Ministério da Educação e Cultura, em conjunto com órgãos privados do período (BIZELLO, 2010). De acordo com Bizello, as revistas ilustradas de circulação nacional $O$ Cruzeiro - e todos os jornais e rádios pertencentes aos Diários Associados de Assis Chateaubriand - e Manchete apoiaram sua candidatura na época da campanha presidencial, assim como os jornais Última Hora, de Samuel Wainer e o Correio de Manhã: todos os veículos que alcançavam grande parte da audiência nacional da época (BIZELLO, 2010). O apoio continuou após a posse, e, dessa forma, JK manteve alianças formais e informais, utilizando-se de favores pessoais para ter ao seu lado os proprietários dos meios de comunicação (BIZELLO, 2010). Segundo Bizello, JK foi capaz de usar ao mesmo tempo seu poder natural e pessoal de conquista e sedução e apresentar suas propostas e estratégias de governo num crescente processo de convencimento dos segmentos sociais e econômicos (BIZELLO, 2010, p. 87).

Como exemplo das relações estabelecidas pelo presidente, podemos apontar as diversas publicações sobre a Belém-Brasília, desde o início de sua construção em 1958 até 1960, todas consonantes com a visão "heróica" divulgada pelo governo. O mito criado em torno da morte de Bernardo Sayão é um reflexo deste processo. ${ }^{6}$ Dois cine documentários da Jean Manzon Films foram produzidos na mesma época, com o objetivo de expor a Amazônia como uma região esquecida, porém, integrada ao restante do país pelo governo federal e cuja natureza selvagem deveria ser combatida. Para o presente texto, selecionamos a série de reportagens publicadas com o título Rodovia da Unidade Nacional, de Mauricio Vaitsman, publicada em 1958. Repórter do Diário da Noite e do Globo, Vaitsman publicou dois livros trazendo todas as notícias por ele produzidas na época da Belém Brasília ambos publicados pela própria SPVEA. O primeiro, que será descrito agora, foi redigido à época da construção, enquanto o segundo (Integração Nacional - A Conquista das Selvas), de 1960, consiste em reportagens sobre a inauguração da Rodovia.

Bernardo Sayão faleceu no término das obras da Belém-Brasília, atingido por uma árvore. 
Um exemplo da visão triunfal presente nessas peças propagandísticas está na própria fala de Juscelino Kubitschek

Ainda não apareceu um Euclides da Cunha para fixar, em páginas que seriam imortais, a epopéia dessa luta contra a floresta. Tudo conspirava para frustrar a intenção dos desbravadores dificuldades de todo género, o mistério da região nunca explorada, a dureza da vida em condições subumanas, os perigos imprevistos, a sede, a fome, as febres, as cobras, os mosquitos e, sobretudo, os carrapatos e o formigão. a estrada ia sendo aberta a serrote, a trator, a facão e a dinamite. Quando um cedro ou uma maçaranduba gigante parecia irremovível, encaixavam-se bananas de dinamite em fendas, abertas nas raízes, e estrondava-se o tronco. A queda de um desses reis da floresta era um espetáculo inesquecível. (KUBITSCHEK, 2000, p. 249).

Uma vantagem da abertura das matas seria o povoamento da região, pois o governo de Goiás, por meio da lei dos posseiros, incentivara a população a se fixar no local: "o dono da terra é quem chega primeiro e se instala" (VAITSMAN, 1958, p. 38). A abertura da estrada parecia para o jornalista, um sonho: "estávamos violando com os nossos pneus uma selva que sempre foi uma barreira para o progresso" (VAITSMAN, 1958, p. 43). A população local também era temida pelos "desbravadores". O tom pitoresco e exótico comanda as descrições. De acordo com o jornalista, $\mathrm{O}$ temor em relação aos nativos também inspirava cuidados, mas os próprios não tinham como tomar conta de si. $\mathrm{O}$ jornalista conta a história de dois indígenas fornecidos pelo Serviço de Proteção ao Índio (para estabelecer contato com os silvícolas locais) que estavam maravilhados com "a tal da injeção" (VAITSMAN, 1958, p. 23). Ao chegarem a Belém, um deles teria comprado uma seringa e injetado com água suja em si mesmo, tendo como conseqüência sua morte. A construção de um “outro" selvagem é forte nos relatos. De forma geral, a população que era descoberta após a passagem das máquinas e tratores é vista como dócil e pouco inteligente, necessitando, conseqüentemente, se integrarem à civilização trazida pela Rodovia Belém Brasília. Por fim, o exotismo e a ferocidade da natureza (tendo como ápice a morte de Bernardo Sayão) dão o tom geral do discurso.

Seria errado pensar que o discurso de destruição presente na 
construção da Belém-Brasília seria único. Como a recente bibliografia mostra, preocupações sobre o mau uso dos recursos naturais habitam o pensamento social desde a época colonial (Pádua, 2007). Não obstante silenciadas por uma ampla propaganda, essas ideias existiam e ocuparam um espaço relevante no debate sobre a agenda pública brasileira a partir dos anos de 1920. Um grupo de pesquisadores, como Alberto Sampaio, Armando Magalhães, Cândido de Mello Leitão e Frederico Hoehne, vinculava preocupações pontuais, como o estabelecimento de reservas naturais, a um projeto mais amplo de nacionalidade. Assim, conseguiram sensibilizar associações cívicas e obter espaço nas instâncias deliberativas do governo Vargas. Esses atores engajados na proteção da natureza apropriaram-se de tradições de pensamento que envolviam um conhecimento científico do mundo natural e a ideia de que esse mundo deveria ser conservado, por motivos econômicos e estéticos (FRANCO, 2009).

Entre os anos de 1920 e de 1940, os conceitos de proteção, conservação e preservação eram intercambiáveis, indicando que a natureza deveria ser protegida, tanto como conjunto de recursos produtivos a ser explorado racionalmente no interesse das gerações presentes e futuras, quanto como diversidade biológica a ser objeto da ciência e contemplação estética. Organizações civis, como a Sociedade Geográfica do Rio de Janeiro, Centro Excursionista Brasileiro e Sociedade dos Amigos das Árvores, assumiram posturas ativas na preservação da natureza. Criticavam o desmatamento, clamavam por reformas na agricultura, defendiam a promulgação de uma lei florestal, distribuíam sementes e ministravam palestras (FRANCO, 2009). O ponto culminante desta mobilização foi a Primeira Conferência Brasileira de Proteção à Natureza, em 1934. A comissão organizadora, formada por funcionários públicos, cientistas, médicos e professores buscava concretizar suas propostas por meio de pressão e influência pessoal sobre as autoridades públicas que ocupavam posições de destaque naquela época. O entusiasmo presente nas reuniões e deliberações do grupo transformou-se em frustração com a não incorporação das propostas à constituição brasileira e à pouca reverberação que estas ideias tiveram no âmbito da sociedade civil. A razão deste fracasso residiria na difusão da ideologia do desenvolvimentismo, que se definia, àquela época, como corrente hegemônica dentro da articulação política do Estado (FRANCO, 2009). De acordo com Dean, o desenvolvimento foi imbuído dos valores positivos de independência 
e auto-realização (DEAN, 2010). Enquanto sistema de crenças era milenarista: o atraso se encerraria, o tradicionalismo daria lugar à modernização e o país alcançaria o desenvolvimento, que constituía um patamar edênico de civilização (DEAN, 2010). Continuando o raciocínio do autor, a idéia de desenvolvimento econômico penetrava a consciência da cidadania, justificando cada ato de governo e de extinção da natureza.

Não foi a primeira e nem a última vez que propagandas fantasiosas sobre o "fim das lendas" amazônicas foram divulgadas. É possível encontrar este discurso, com cores autoritárias, nas propagandas da Transamazônica em anos posteriores. Por fim, importante destacar que o estudo da construção da rodovia Belém-Brasília serve como um exemplo de como o desenvolvimento para a região amazônica foi levado e liderado pelos políticos nacionais. A construção da estrada demonstra, inicialmente, o grande apoio que Kubitschek possuía junto aos meios de comunicação, uma parceria que não é inédita em nossa história republicana. Além disto, a BR-14 demonstra um certo tipo de desenvolvimento que ignorou as particularidades locais e reforçou uma antiga noção iluminista: que o progresso só viria em contraposição à natureza.

\title{
Postwar amazon and the Construction of THE BELÉM- BRASÍLIA MOTORWAY
}

\begin{abstract}
This work aims at reviewing state policies for the Amazon region after World War II, which culminated in the construction of the Belém-Brasilia motorway, one of the biggest state interventions in the region. The intention here is problematizing the history of the region, intertwined with the national and international context, against the emergence of the notion of development as emblem of industrialised countries. In name of development, various public policies were formulated, such as the building of roads to put an end to an alleged "historical isolation". Such an idea reinforced the current image of the Amazon: a scarcely populated and diseased region, characterised by wilderness and, mainly, an obstacle to progress. This representation of the Amazon region is not a novelty: on the contrary, it is based on the adaptation of old myths and constructions to this new period of development. Initially, we will trace an outline of state interventions and political debates involving the Amazon in the Second Republic (1946-1964). Later one, the focus will shift on the construction of the Belém-Brasilia motorway, one of the main accomplishments of Kubitschek's government.
\end{abstract}




\section{KEYWORDS: Amazon. Belém-Brasília. Development. Power. State Intervention.}

\section{Referências}

ANDRADE, R. P. A Amazônia vai ressurgir! Saúde e saneamento na Amazônia no Primeiro Governo Vargas (1930-1945). Dissertação (Mestrado em História das Ciências e da Saúde) - Casa de Oswaldo Cruz/Fiocruz, Rio de Janeiro, 2007.

ANDRADE, R. P. A Amazônia na era do desenvolvimento: saúde, alimentação e meio ambiente (1946-1966). Tese (Doutorado em História das Ciências e da Saúde) - Casa de Oswaldo Cruz/Fiocruz, Rio de Janeiro, 2012.

BRASIL, Diário do Congresso Nacional: 27/08/1958; 06/04/1959; 30/11/1959.

BRASIL, Constituição dos Estados Unidos do Brasil, 1946.

BARRETO, R. M. Aventura através do progresso. Rio de Janeiro, SPVEA, 1965.

BIZELLO, M. L. Imagens de convencimento: cinejornais e filmes institucionais nos anos JK. ArtCultura (UFU) versão on-line, v. 11, p. pdf, 2010.

CAMPOS, A. L. V. Políticas internacionais de saúde na Era Vargas - O Serviço Especial de Saúde Pública, 1942-1960. Rio de Janeiro, Editora Fiocruz, 2006

CPDOC/Arquivo Getúlio Vargas, campanha eleitoral de 1950: 1950.08/09.00/2

DEAN, W. A ferro e fogo: a história e a devastação da Mata Atlântica brasileira. São Paulo, Companhia das Letras, 2010.

FRANCO, J. L. A.; DRUMMOND, J. A. Proteção à natureza e identidade nacional no Brasil - anos 1920-1940. Rio de Janeiro: Editora Fiocruz, 2009.

KUBITSCHEK, J. Por que Construí Brasília. Brasília, Senado Federal - Coleção Brasil 500 Anos, 2000.

MOREIRA, V. M. L. Os anos JK: industrialização e modelo oligárquico de desenvolvimento rural. In FERREIRA, Jorge \& DELGADO, Lucília de Almeida Neves. O Brasil Republicano - o tempo da experiência democrática - da democratização de 1945 ao golpe civil-militar de 1964. Rio de Janeiro, Civilização Brasileira, 2003.

MONTEIRO, M. A.; COELHO, M. C. N. "As políticas federais e reconfigurações espaciais na Amazônia”. Novos Cadernos NAEA, v. 7, n. 1, p. 93, jun. 2004.

ROLIM, A. Transbrasiliana - Poema Brasilista. Rio de Janeiro, 1960. Sachs, Wolfgang. Introduction. In: Sachs, Wolfgang (Ed.). The Development Dictionary - A Guide to Knowledge as Power. New York: Zed Books, 1999.

SECRETO, M. V. “A ocupação dos 'espaços vazios’ no governo Vargas: do 'discurso do Rio Amazonas’ à saga dos soldados da borracha”. Estudos Históricos, n40, jul-dez. 2007, pp. 115-135 
s/autor, "Plano Salte", Abreu et alii, Dicionário Histórico-Biográfico Brasileiro pós1930. Rio de Janeiro, FGV/CPDOC, 2000, Versão CD-ROM

SILVA, R.; HOCHMAN, G. Um método chamado Pinotti: sal medicamentoso, malária e saúde internacional (1952-1960). Hist. cienc. saude-Manguinhos [online]. 2011, vol.18, n.2 [citado 2013-11-17], pp. 519-544. Disponível em: http://goo.gl/tbYJH0.

VELHO, O. G. Frentes de Expansão e estrutura agrária - estudo do processo de penetração em uma área da Transamazônica. Rio de Janeiro, Centro Edelstein de Pesquisas Sociais (Edição online), 2009.

VAITSMAN, M. Rodovia da unidade nacional. Rio de Janeiro, SPVEA, 1958.

Data de recebimento: 7/10/2014

Data de aceite: $11 / 11 / 2014$ 